\title{
Organizational Health Among Catholic Religious Congregations*
}

\author{
Paula Benevene \\ Università LUMSA, Rome, Italy \\ Michela Cortini \\ Università G. d’Annunzio of Chieti Pescara, Pescara, Italy
}

\begin{abstract}
Diversity among organizations may promote a better organizational performance, and diversity management can be used as a competent strategic management conceptual framework in the governance of religious congregations, just as for other organizational forms. Catholic religious congregations are currently undergoing profound changes: They are more and more multicultural; The younger generations have a different understanding of their consecrated in comparison with the previous generations; In addition, they deal with a growing role of lay people in the Church. The study investigated the specific challenges faced by governance of religious congregations, as particular organizational form, in terms of organizational health. A semi-structured interview was administered to a sample of catholic consecrated people $(n=40)$. Differences emerged among participants coming from different cultures as well as between younger and older members on their representation and perception of normative organizational control, and differences emerged also on the role and the tasks expected from leaders and followers.
\end{abstract}

Keywords: diversity management, corporate governance, catholic religious congregations

\section{Catholic Congregations and Diversity}

It is a fact that catholic congregations are facing an era of meaningful changes. According to the Annuarium Statisticum Ecclesiae (Ufficio Centrale Statistica del Vaticano, 2009), the number of consecrated priests, belonging to a congregation, declined from 158,000 to 136,000 between the year 1978 and the year 2006. This trend appears to be quite relevant in Northern America (-36\%), as well as in Europe (-22\%) and, to a lower extent, also in Latin America (-8\%). Vice versa, the number of consecrated people in Africa is quite stable while is rapidly growing in Asia (+57\%). Facts and figure about the worldwide presence of nuns show a similar evolution: they were 740,000 in the year 2008 and, during the previous eight years their presence in Europe, Oceania and America they declined between $15 \%$ and 17\%, while in Africa and in Asia respectively they rose a whopping

\footnotetext{
* Both the authors have planned the study and discussed together about the different issues related to the present paper. Dr. Benevene has written the paragraphs: 1, 2, 3, 5, 6 and Dr. Cortini has written the paragraphs 4, 7, 8, 9, 10. The authors have written together the paper's conclusions.

Paula Benevene, Ph.D., Researcher, Facoltà di Scienze Della Formazione, Università LUMSA.

Michela Cortini, Ph.D., Assistant Professor, Facoltà di Psicologia, Università G. d’Annunzio of Chieti Pescara.

Correspondence concerning this article should be addressed to Michela Cortini, University of G. d'Annunzio, via dei Vestini, 33, Chieti scalo, Chieti, Italy. E-mail: cortini@unich.it.
} 
$21 \%$ and $16 \%$. On the opposite, the number of lay people among the catholic church is growing fast: they were 37,000 in the year 2008, that is +33\% in comparison with the year 2000 (Ufficio Centrale Statistica del Vaticano, 2010). Those data show how catholic congregations are facing big challenges posed by their multiculturality, as well as the growing role plaid by lay people, and the differences among younger and older generations, on relevant issues such as education (younger generations being more educated than older ones) and their approach to the issue of obedience and authority (younger generations, namely the post Vatican II generation, being more critical to obedience and authority than older generations).

\section{Diversity Management}

Literature review shows that diversity among organizations may promote a better organizational performance (see e.g., Moore, 1999; Richard \& Johnson Brown, 2001; Watson, Kamales, \& Larry, 1993). Diversity can improve performance through enriching the decision-making process because of the broader range of ideas and alternatives that can emerge from members (Ely, 2004). On the other hand, diversity can also have negative outputs, causing problems in terms of integration, coordination, motivation and conflict management (Jehn \& Chatman, 1993).

The success (or the failure) of diversity on organizational performance depends on a large extent from its management as well as context factors such as task characteristics, organizational culture, human resources practices, team process (Jackson, Aparna, \& Erhrd, 2003; Kochan et al., 2003; Pitts, 2005). In effectively managing diversity, the most crucial roles are therefore played by leadership. Diversity management can reduce the potential negative effects of diversity and enhance positive effects (Cox, 1993; Stewart \& Johnson, 2009).

\section{Management of Religious Congregations}

Kotler (1982) identifies two types of Non-Profit organizations (NPOs): public (such as government agencies) and private (e.g., charities). The latter have received far less attention in the management literature, in spite of the growing interest in the not-for-profit sector (Adeyemy-Bello, 2001).

Moreover, research and studies on management of religious congregations as particular organizational forms are still very scarce. On the contrary, those entities should attract more managerial literature for several reasons: There are real organizational problems at their grass roots, since they must find a way "to reconcile religious teaching with practical organizational consideration, to build institutions which are capable of responding and surviving in contemporary society, but which remain a true reflection of religious principles” (Harris, 1998, p. 5); Secondly, as a consequence of the substantial reduction of state interventions, many religious congregations are facing an increasing request for services delivery and regard this as a part of their religious mandate; Thirdly, religious congregations are a relevant part of the not-for-profit sector, that is organizations which have to deal with issues such as preventing volunteer burnout, reliance on normative organizational control, accountability to several and different stakeholders (donors, paid staff, members, volunteers).

\section{Religious Congregations and Diversity Management}

Diversity management interests all sorts of organizations: for-profit, public and NPOs, nonetheless, it has mainly been approached in the for-profit and public sectors. 
Recently, the international literature on management has given some space to the issue of diversity within religious congregations. Christerson and Emerson are among those who first dealt with this topic, publishing in 2003 an article in the journal Sociology of Religion. Before, as they explain, there was a sort of theoretical and empirical prejudices which did not allow addressing the issue of diversity among religious congregations. In fact, their members were considered as people who share a religious tradition, faith and practices, but also the same culture, therefore the diversity management was not an issue.

This was obviously a mistake, since, as a matter of fact, members of religious congregations are people coming more and more from different cultures, traditions, languages, habits, values.

More recently, following the creation of the "Management, spirituality and religion special interest group of the academy of management”, the scientific community has paid attention to the issue of spirituality in the workplace. The group started its activity as a result of the debate started between Miller $(2002,2006)$ on the one side and Gomez and Moore (2006) on the other one. In 2002, Miller published on the Strategic Management Journal a pioneer article in which he used strategic management tools (SMT) to explain the competition amongst religious organizations as well as their evolution. Gomez and Moore (2006) replied to Miller's article in the Journal of Management, Religion and Spirituality Research, where they questioned the appropriateness of his approach, arguing that beyond the novelty and the peculiarity of the topic, religious organizations could not be treated as for-profit organizations and therefore explaining their organizational life in terms of market-like dynamics. Consequently, they concluded that strategic management tools are limited in describing religious organizations' strategies. Miller (2006, p. 3) replied in the same issue of the Journal of Management, Religion and Spirituality Research, affirming that on the one hand, it is true that management literature does not offer a comprehensive theory of religious organizations, only a distinct and potentially insightful vantage point; but, on the other hand, he stressed that it is neither appropriate nor desirable that management theory remains unchanged as a result of its encounter with religious organizations. The debate on management and religious organizations has the potential to be a generative process, changing both the management theory and the practices adopted by religious congregations.

\section{Theory and Hypothesis}

The general goal of this explorative research is to start an understanding of the attitudes and the representations of diversity management among catholic religious congregations. The majority of the researches developed in the diversity management area have focused either on for-profit or on public organisations, but there is an increasingly and recognised need for research studies that focus on the management of not-for-profit ones. There have been various theoretical and practical debates on whether and to which extent it is possible to apply models and theories that have previously been tested in other organizational sectors (Anheier, 2005). Therefore, it is essential to develop the NPOs management on a theoretical basis by studying and verifying the reliability and applicability of the management theories and practices that are already being used.

It is a fact that most NPOs appear to be still a bit too far from professional management, as well as from auditing and accounting for their (human, financial, logistic) resource and processes and these organizations might benefit from the application of management theories and practices already endorsed by business enterprise and public agencies (Helming, Jegers, \& Lapsley, 2004). Therefore, pratictioners and managers/leaders of NPOs might find researches and studies on management to be meaningful and useful (Adeyemi-Bello, 2001; Hatten, 
1982). On the other hand, NPOs and therefore catholic congregations can offer an interesting field where the knowledge that has already being accumulated on the management of the for-profit and the public sector could be further verified and eventually developed (Drucker, 1990). It is therefore significant to develop a more deep knowledge on the diversity management among third sector, in order to understand which the critical areas, in need of intervention are, and which instead are the positive models, behaviour and practices that might be eventually mutuated from one sector to another. In add, while monitoring diversity management, not-for-profit, for-profit and public managers may have a wider and more useful picture of their resources and their organization's performance, addressing therefore a relevant issue for the development of their organizations.

We therefore developed the following research questions:

RQ1: What kind of diversity management is challenging religious organization, and which are the values associated to the concept of diversity?

RQ2: How they approach diversity among them? Do female and male congregations differ in their approach to their community live?

\section{Research Design}

Semi-structured interviews were administered to 40 consecrated people, from 9 nationalities and belonging to 36 different catholic congregations, both female $(N=30)$ and male $(N=10)$, aged 25-49 (mean: 37.8).

Participants were asked to talk freely about:

- The strengths and the weaknesses of their organizational life;

- The changes and the challenges that their own congregations are facing;

- Which were the critical moments and how crisis were dealt.

Interviews were collected during the academic year 2009-2010 in central Italy. The interviews have been taped and transcribed. On transcriptions, we run a content analysis, in order to investigate the discursive construction of religious convivence and perform a depth-in analysis of the way by which religious congregations face diversity management. We have decided to work only on participants' words, so that before run the content analysis, we have purged the text for the words of the interviewers.

\section{Content Analysis}

The quantitative content analysis has been run through the software T-Lab ${ }^{1}$ (analysis of word occurrence and co-occurrences, Markovian Sequences analysis and linguistic specificity analysis). Before performing the text analysis, we prepared it doing what is known under the name of lemmatization. That is a reorganization of the T-LAB database, creating different tables subsequently used to analyze the data. Words having the same meaning root, for example, "family" and "familial" were clustered together. Only the words (lemmas or categories) considered interesting for the subsequent analyses, like community, culture, diversity and so on underwent this process.

\section{Analysis of Word Occurrence and Co-occurrence}

The most cited word is “community”, with 372 occurrences, and this result is even higher if we consider that

\footnotetext{
${ }^{1}$ For further info about the software T-lab, visit the webpage www.tlab.it.
} 
the third most quoted word is "convivence", with 204 occurrences. Among the most cited words, there are also "diversity" and "culture" (respectively, with 271 and 99 occurrences), as well as "religious", with 113 occurrences, "family", with 94 occurrences and "difficulties" with 88 occurrences. We may sum up this first result in terms of a focus on the religious life. In responding the interview questions, participants did refer to their daily life, the life of their community seen as a form of family life.

As a second step, we have run a co-occurrences analysis using as stimulus word "diversity", in order to verify which words come up together with "diversity” by the highest index of association. The results are shown in two ways: with a graphic output of T-Lab (see Figure 1), where the more two words co-occur the more they are close in the dimensional space); and a statistical table (see Table 1) illustrating the analysis of the indexes of association (Cosine's coefficient) which, in brief, calculates the associations of co-occurrences of a given word with another one on the total probability a word has to come with whatever else of the dataset. This peculiar type of analysis is used to verify how the mental representation of diversity, thanks to the analysis of its discursive traces.

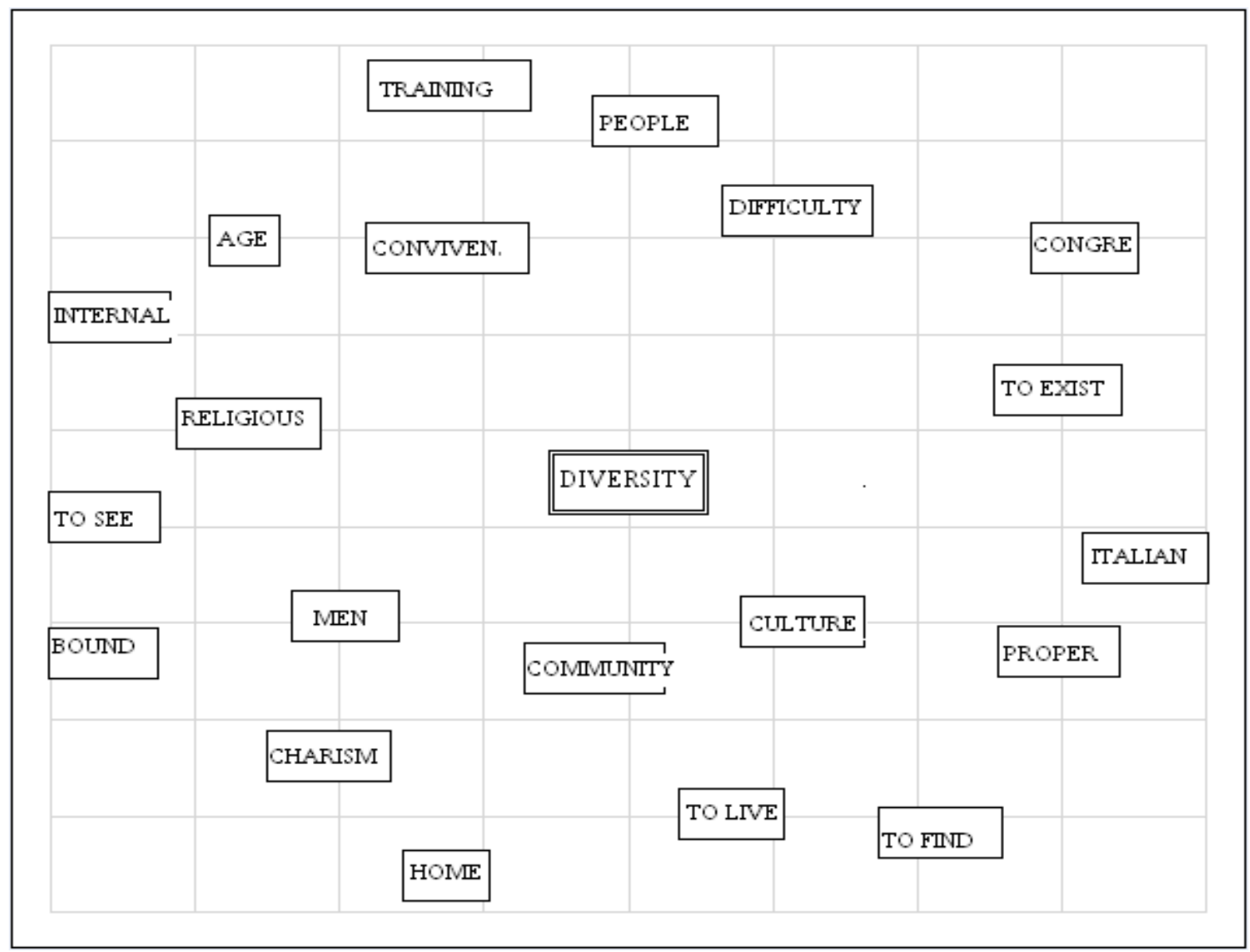

Figure 1. Graphic output of T-Lab.

It is interesting to note the high association "diversity” has with "culture” (Cosine’s coefficient 0.36), also in terms of mere co-occurrences (40). This means then when participants talk about diversity, they firstly think of the dimension of culture as the main source of diversity. In addition, the high association with "difficulties" 
(Cosine's coefficient 0.21) suggests that in the daily-life of religious people their diversity brings some difficulties in terms of relationships management. Finally, participants refer to training ("formazione") and to experience ("esperienza”), with a cosine’s coefficient of 0.15 , as a way to facilitate diversity management. In this sense, it is worthy of our attention of the self-awareness that participants show in terms of training needs: they do recognize that culture can lead to some problems of convivence and they call for specific training. Finally, it is interesting the association with "charism” (Cosine’s coefficient 0.19), which clarifies that even when religious people face many or serious difficulties, they feel pushed to solve it positively, since their convivence is a fundamental expression of their religious choice. This is well explained in the following example, which is extracted from one of the interviews.

Table 1

Indexes of Association (Cosine's Coefficient)

\begin{tabular}{llrcc}
\hline Lemma & Coeff. & Occ. & Co-occ. & Chi $^{2}$ \\
\hline Culture & 0.365 & 99 & 40 & 63.858 \\
Comunità & 0.355 & 372 & 79 & 12.806 \\
Men & 0.282 & 80 & 34 & 22.539 \\
Religious & 0.245 & 1113 & 33 & 8.546 \\
Convivence & 0.238 & 204 & 41 & 1.427 \\
Difficulties & 0.214 & 88 & 25 & 6.57 \\
To exist & 0.212 & 24 & 14 & 19.527 \\
Proper & 0.195 & 98 & 26 & 1.529 \\
To live & 0.193 & 124 & 29 & 0.246 \\
Charism & 0.193 & 29 & 14 & 12.496 \\
To see & 0.181 & 89 & 23 & 1.01 \\
Age & 0.18 & 17 & 10 & 14.083 \\
People & 0.174 & 80 & 21 & 1.081 \\
Congregations & 0.165 & 34 & 13 & 5.709 \\
Italian & 0.164 & 13 & 8 & 12.342 \\
To find & 0.16 & 62 & 17 & 1.293 \\
Home & 0.159 & 49 & 15 & 2.437 \\
Bound & 0.157 & 18 & 9 & 8.677 \\
Internal & 0.157 & 57 & 16 & 1.464 \\
Training & 0.152 & 40 & 13 & 2.888 \\
Experience & 0.15 & 48 & 14 & 1.674 \\
\hline & & & & \\
\end{tabular}

Ex. 1: "What characterizes and enriches our convivence of three religious families, is primarily a charismatic reason. Sometimes we have difficulty in managing our convivence... sometimes it is difficult to take decisions, we all have different sensitivity, different opinions... well, it is necessary to be willing to build up this convivence you just wanting this communion. But when our human reasons for sharing our lives are not strong enough, the charismatic motivation pushes us to stay together. We can understand the beauty of living together only if we understand deeply the reason why we are together, which is really a fundamental reason”. (female respondent)

\section{Results of Sequence Analysis}

This first result suggested us to investigate more in deep the word associations of the lemma "convivence"; 
for this reason, we run a sequence analysis (see Table 2). Sequence analysis is a Markovian analysis of the sequences concerning the lexical units presented in the network defined by the corpus. Sequences are syntagmatic relationships between the lexical units under analysis, and each of them, for each occurrence within the corpus chain, has a predecessor and a successor, which are respectively the lexical unit that comes before it and the lexical unit that comes after it. Beginning from a matrix in which all the predecessors and all the successors of each lexical unit are recorded, T-Lab calculates the transition probabilities (Markov chains) between the lexical units analyzed. The following table shows the sorted list of predecessors (the first) and successors (the second) of the lexical unit "convivence". The list is in descending order according to the probability values ("PROB”). For example, in the following table, the probability that "changing” will follow "convivence" is equal to 0.015 , that is $1 \%$ and the possibility that "diversity" comes before "convivence" is 0.064 , that is $6 \%$ and that "difficulties" comes before "convivence" is 0.015 , that is $1 \%$.

Table 2

Markovian Sequence Analysis

\begin{tabular}{ll|ll}
\hline Successors & PROB & Predecessors & PROB \\
\hline Men & 0.064 & Different & 64 \\
Community & 0.03 & Rightly & 0.03 \\
To change & 0.015 & To live & 0.025 \\
Person & 0.015 & Our & 0.025 \\
Family & 0.015 & Community & 0.025 \\
To think & 0.01 & Difficulties & 0.015 \\
Difficulties & 0.01 & Internal & 0.01 \\
Different & 0.01 & To talk & 0.01 \\
To help & 0.01 & Years & 0.01 \\
To ask & 0.01 & To help & 0.01 \\
To live & 0.01 & Before & 0.01 \\
To talk & Sure & 0.01 \\
Rightly & To ask & 0.005 \\
Religious & To understand & 0.005 \\
Our & 0.01 & To change & 0.005 \\
To try & 0.01 & Christ & 0.005 \\
To create & Experience & 0.005 \\
Culture & Family & 0.005 \\
& 0.01 & & 0.005 \\
\hline
\end{tabular}

The results of the sequence analysis show the use of a group of words as both predecessors and successors, like "difficulties" and "change". It seems that in the mental representation of religious people, the convivence is facilitated by a process of individual changes, though this cannot prevent or delete all difficulties and problems, requiring further changes. In this light it is easy to understand the reason why several participants made reference to convivence as a part of their religious life. This is well expressed in the following extract.

Ex. 2: "The convivence is a tool; it is instrumental to achieve our objective, which is to live as Christ is a means. The convivence is nota $\mathrm{n}$ aim, but a tool...”. (female respondent) 


\section{Results of Linguistic Specificity}

Linguistic specificity analysis was run using as occurrence-point 1 time (this means that we have taken into account all the words used, even when they had been used just once), to verify if there were relevant differences among female and male participants (see Table 3).

Female respondents refer to convivence using a group of discursive contents which male respondents do not use at all, and these are a group of words which make reference to the other religious people living with them, like "mother" or "sisters" (in addition, with a pretty high index of occurrence) and to the authority of their community. It seems, in this way, that they have a very practical and experience-based idea of what convivence is. In addition, it is enlightening the reference to both the words "decision" and "to decide" which stress the voluntary choice of belonging to a religious congregation and transforms, in some way, the "problem" of diversity management in a matter of choice and of challenge. This is clear in the following textual example.

Ex. 3: "Surely the convivence is a fundamental factor for the religious congregations, since they have as its foundation the consecrated life and community life. It means that cohabitation is one of the two pillars of our lives: on one hand there is the prayer, then the relationship with God and the other hand there's the practice, the implementation of this. Therefore living together with people you didn't choose means that you're following a God's project. The convivence is beautiful, but it is not easy to live with people you didn't choose. Each of us is different from the others, but the same difficulties, in some way, are faced also in a marriage, because also a couple is made of two different persons... Failure to choose the people with whom you live are a choice following another, more important choice: it is part of the three vows we make, when we joined the congregation: poverty, obedience and chastity. Therefore, obedience means that you live everyday with your sisters, and more closely with your mother superior, but you didn't choose the people with whom you live”. (female respondent)

Differently from what happens in families, where two people chose each other, those who choose to follow her religious vocation, have to come to terms with the fact that someone else decides for her where and whom she is going to live with.

For what concerns male respondents, there are at least two interesting data to be considered. First of all, the reference to the concept of sainthood (with the word "sainthood" and "sanctification"), stressing the idea that the convivence, with its organizational daily life, is the way, the path towards they have to become saint. In addition, it seems that, in comparison to the female counterpart, male respondents stress much more their individuality and conceive the community life as a way to build personal relationships, but with some individual space or "distance" among different members. This emerges from the exclusive use of words such as "oneself", "individualistic”, and “identity”. Some textual transcriptions clearly illustrate this approach.

Ex. 4: "Female convivences are different from male ones. Male communities are a mixture of rationality and logic, directivity and clarity; they are faster when taking a decision but also more superficial, in comparison with us (men); these are typically male characteristics. Female communities are more prone to emotions, feelings, intuition, sharing and giving”. (male respondent)

Ex 5: "Men tend to be more direct, they are much straighter, then they can hang better tense situations. They are friends in spite of the fact that they sometimes have bad arguments. But this has nothing to do with being nuns or priests... this is beacuse men are men and women are women. Women are more interested in feelings, in sensibility but they show also variability of mood. Men are more interested in power, in organizational issues, in politics”. (female respondent)

In other words, it seems that female suffer more from being in convivence with others but are perhaps unable to conceive themselves as totally separate from the other consecrated women; on the opposite, male participants 
are more able to keep some distance among them.

Table 3

Exclusive Specificity

\begin{tabular}{|c|c|c|c|c|c|}
\hline \multicolumn{4}{|c|}{ Males } & \multicolumn{2}{|c|}{ Females } \\
\hline Word & Occurrence & Word & Occurrence & Word & Occurrence \\
\hline Human & 37 & Foundamentaly & 10 & Human & 37 \\
\hline Mother & 35 & Sainthood & 10 & Mother & 35 \\
\hline Aim & 25 & Emotional & 4 & Aim & 25 \\
\hline To decide & 22 & Millenium & 4 & To decide & 22 \\
\hline Opportunity & 22 & To relate & 4 & Opportunity & 22 \\
\hline Advice & 18 & Of-this-kind & 4 & Advice & 18 \\
\hline To repeat & 17 & Source & 4 & To repeat & 17 \\
\hline Knowledge & 17 & Practice & 4 & Knowledge & 17 \\
\hline Sisters & 15 & To draw back & 4 & Sisters & 15 \\
\hline Novitiate & 15 & Oneself & 4 & Novitiate & 15 \\
\hline To respect & 14 & Distance & 4 & To respect & 14 \\
\hline Authority & 14 & Ignazio & 3 & Authority & 14 \\
\hline Motivation & 13 & Reciprocity & 3 & Motivation & 13 \\
\hline To recognize & 13 & Table & 3 & To recognize & 13 \\
\hline To follow & 13 & To embrace & 3 & To follow & 13 \\
\hline To explain & 13 & Sanctification & 3 & To explain & 13 \\
\hline To live & 13 & Models & 3 & To live & 13 \\
\hline Maximum & 13 & Individualistic & 3 & Maximum & 13 \\
\hline Poor & 12 & Sea & 3 & Poor & 12 \\
\hline Motherhood & 12 & Trine & 3 & Motherhood & 12 \\
\hline To train & 11 & Identity & 3 & To train & 11 \\
\hline Sensibility & 11 & Manor & 3 & Sensibility & 11 \\
\hline Personal & 11 & Set & 3 & Personal & 11 \\
\hline Field & 10 & Aim & 3 & Field & 10 \\
\hline Challenge & 10 & High & 3 & Challenge & 10 \\
\hline Initially & 10 & Good & 2 & Initially & 10 \\
\hline Decision & 10 & & & Decision & 10 \\
\hline
\end{tabular}

\section{Conclusion}

The aim of the present study is to explore the discursive construction of diversity and convivence among religious congregations seen as organizations. In particular, we wanted to explore the dimension of diversity management, which is becoming a core issue in the nowadays organizational theory and practice, as it is seen and lived by religious people.

In terms of results, it is important to stress that when asked to talk about the issue of diversity, participants show to conceive it as definitively related to some cultural differences. Some of our respondents actually did mention also problems of managing people belonging to different generations and cohorts but the most challenging diversity is definitively linked to cultural differences. 
When dealing with diversity, consecrated people feel to be expected to solve problems in terms of personal, and not organizational, responses. The leadership seems to be perceived as having the last word when the congregation or a group faces a big crisis, while the responsibility of the daily governance of difficulties lies mainly in individuals' behaviour. There is a perception that self-training is important in terms of successfully addressing the issue of diversity, but the organizational dimension does not appear to be regarded as relevant. In this light, diversity is perceived as challenge and an opportunity to live more in deep their religious choice.

The good quality of convivence among quite different people, though sometimes difficult, is mainly regarded as a tool to further develop one's religious vocation. This specific result is interesting, considering the potentiality that the religion domain may have in changing the management practice, according to Miller (2006) who suggested that diversity management seems to be a problem only for managers, while for co-workers is rarely seen as an occasion of learning. More in general, findings suggest that training is required among religious congregations, in order to raise more awareness, and competence on diversity management and organizational dynamics.

The linguistic specificity analysis, we run to understand the differences between female and male participants in terms of their representations of diversity and convivence, seems to confirm a tradition of studies within the gender studies, according to which women and men conceive differently their personal relationships. It might be worthy to further develop the knowledge about the concrete convivence of male, female and mixed communities.

\section{References}

Adeyemi-Bello, T. (2001). The impact of leadership style on organizational growth. Work Study, 50(4), 150-154.

Anheier, H. K. (2005), Nonprofit organizations: Theory management policy. London: Routledge.

Christerson, B., \& Emerson, M. (2003). The costs of diversity in religious organization: An in-depth case study. Sociology of Religion, 64(2), 163-181.

Cox, T. (1993). Cultural diversity in organizations: Theory, research and practices. San Francisco, C.A.: Berrett-Koehler.

Drucker, P. F. (1993). Postcapital society. New York, N.Y.: Harper and Collins.

Ely, R. J. (2004). A field study of group diversity, participation in diversity education programs, and performance. Journal of Organizational Behavior, 25(6), 755-780.

Gomez, P. Y., \& Moore, R. (2006). From strategy of religions to religion of strategy: Comments on Miller’s “Competitive Strategies of Religious Organizations”. Journal of Management, Spirituality and Religion, 6(3), 199-213.

Harris, M. (1998). Organizing God's work: Challenges and synagogue. New York, N.Y.: St Martin's.

Hatten, M. L. (1982). Strategic management in not-for-profit organisations. Strategic Management Journal, 3(2), 89-104.

Helming, B., Jegers, M., \& Lapsley, M. (2004). Challenges in managing non-profit organizations: A research overview. Voluntas, 15(2), 101-116.

Jackson, S. E., Aparna, J., \& Erhrd, N. L. (2003). Recent research on team and organizational diversity: SWOT analysis and implications. Journal of Management, 29(6), 801-830.

Jehn, K. A., \& Chatman, J. A. (1993). The influence of proportional and percentual conflict composition on team performance. International Journal of Conflict Management, 11(1), 56-73.

Kochan, T., Bezrukova, K., Ely, R., Jackson, S., Joshi, A., ... Thomas, D. (2003). The effects of diversity on business performance: Report of the diversity research network. Human Resource Management, 42(1), 3-21.

Miller, K. D. (2002). Competitive strategies of religious organizations. Strategic Management Journal, 23(5), 435-456.

Miller, K. D. (2006). A case for including religious organizations in management research. Journal of Management, Spirituality and Religion, 6(3), 214-230.

Moore, S. (1999). Understanding and managing diversity among groups at work: Key issues for organisational training and development. Journal of European Industrial Training, 23(4/5), 208-218.

Pitts, D. W. (2005). Diversity, representation, and performance: Evidence about race and ethnicity in public organizations. Journal 
of Public Administration Research and Theory, 15(4), 615-631.

Richard, O., \& Johnson Brown, N. (2001), Understanding the impact of human resource diversity practices of firm performance. Journal of Management, 13(2), 177-195.

Stewart, M. M., \& Johnson, O. (2009). Leader-member exchange as a moderator of the relationship between work group diversity and team performance. Group Organization Management, 34(5), 507-535.

Ufficio Centrale Statistica del Vaticano. (2009). Annuarium statisticum ecclesiae. Città del Vaticano: Libreria Editrice Vaticana. Ufficio Centrale Statistica del Vaticano. (2010). Annuarium statisticum ecclesiae. Città del Vaticano: Libreria Editrice Vaticana.

Watson, W. E., Kamales, K., \& Larry, K. M. (1993). Cultural diversity’s impact on interaction process and performance comparing homogeneous and diverse task groups. Academy of Management Journal, 36(3), 590-602.

Wrench, J. (2007). Diversity management can be bad for you. Race \& Class, 46(3), 73-84. 